\title{
Torque Ripple Minimization of Doubly Salient Permanent-Magnet Motors
}

\author{
K. T. Chau, Senior Member, IEEE, Qiang Sun, Ying Fan, Student Member, IEEE, and \\ Ming Cheng, Senior Member, IEEE
}

\begin{abstract}
Due to the nature of salient poles in both the stator and rotor, the doubly salient permanent-magnet (DSPM) motor suffers from severe torque ripples. In this paper, the torque ripple of DSPM motors is analyzed, and the torque ripple factor is newly derived. A new approach, namely the conduction angle control, is proposed to minimize the torque ripple. Moreover, the genetic algorithm is employed to optimize the corresponding control angles. Computer simulation and experimental results are given to verify the proposed approach.
\end{abstract}

Index Terms-Doubly salient motors, permanent-magnet (PM) machines, torque ripple.

\section{INTRODUCTION}

$\mathbf{R}$ ECENTLY, a new class of brushless motors, termed the doubly salient permanent-magnet (DSPM) motor, has been introduced [1], [2]. The DSPM motor incorporates the merits of both the PM brushless motor and the switched-reluctance (SR) motor. First, the PMs are located in the stator so that the possibility of irreversible demagnetization under high operating temperature can be eliminated, and the problem of mechanical instability can be solved. Second, the rotor is the same as that of the SR motor so that the advantages of simple configuration and mechanical robustness can be retained.

Since its advent, the development of the DSPM machine has taken on an accelerated pace. In [3], nonlinear magnetic circuit analysis was proposed to facilitate its design and optimization. In [4], finite-element analysis was employed to determine its static characteristics. In [5], its design and performance as an automotive generator were revealed. In [6], a split-winding arrangement was developed to extend its constant-power motoring range.

Similar to the SR motor, the DSPM motor suffers from severe torque ripples because of the nature of salient poles in both the stator and rotor. These torque ripples cause mechanical vibration and acoustic noise, which greatly affects its acceptability. Nevertheless, to the best of authors' knowledge, relevant investigations such as the formulation and minimization of its torque ripples are absent in literature.

Manuscript received October 30, 2003; revised February 19, 2004. This work was supported in part by a grant from the Research Grants Council of Hong Kong Special Administrative Region, China, under Project HKU 7035/01E, and in part by a grant from the National Natural Science Foundation of China (NSFC) under Projects 50377004 and 50337030. Paper no. TEC-00320-2003.

K. T. Chau and Y. Fan are with the Department of Electrical and Electronic Engineering, The University of Hong Kong, Hong Kong, China.

Q. Sun and M. Cheng are with the Department of Electrical Engineering, Southeast University, Nanjing 210096, China.

Digital Object Identifier 10.1109/TEC.2004.841507
In this paper, the torque ripple of DSPM motors will be analyzed. The key is to analytically derive the torque ripple factor; hence, proposing the conduction angle control to suppress the operating torque ripple. Then, the genetic algorithm (GA) will be employed to optimize the control angles in such a way that the torque ripple can be minimized. Throughout the analysis and experimentation, an 8/6-pole DSPM motor will be adopted for exemplification.

In Section II, the torque ripple of DSPM motors will be analyzed, hence, formulating the operating torque ripple. In Section III, the influence of conduction angles on the operating torque ripple will be revealed. In Section IV, the GA will be adopted to minimize the torque ripple.

\section{TORQUE RIPPLE ANALYSIS}

Similar to the SR motor, the DSPM motor exhibits severe torque ripples. There are three major categories of torque ripples.

- The operating torque ripple is due to the nature of doubly salient operation. It is present even at ideal conditions of operation.

- The practical torque ripple is due to the nonideality of the motor characteristics, such as the magnetic saturation, the fringing effect, the nonrectangular stator winding current, and the finite mutual inductances.

- The manufacturing torque ripple is due to the motor imperfection occurring during manufacturing, such as the asymmetry between positive and negative cycles within a phase, the asymmetry among different phases, and the eccentricity of rotating parts.

\section{A. Operating Torque Ripple}

Fig. 1(a) shows the configuration of a four-phase 8/6-pole DSPM motor, namely eight salient poles in the stator $\left(p_{s}=8\right)$, six salient poles in the rotor $\left(p_{r}=6\right)$, and two pieces of PMs located in the stator. Fig. 1(b) shows its theoretical operating waveforms of the PM flux linkage $\Psi_{\mathrm{pm}}$ and stator winding current $i$ with respect to the rotor position $\theta$.

The system matrix equation describing the four-phase 8/6pole DSPM motor is expressed as

$$
\bar{V}=\bar{R} \bar{I}+\frac{d \bar{\Psi}}{d t}
$$

where $\bar{V}=\left[v_{a}, v_{b}, v_{c}, v_{d}\right]^{T}, \bar{R}=\operatorname{diag}\left[r_{a}, r_{b}, r_{c}, r_{d}\right], \bar{I}=$ $\left[i_{a}, i_{b}, i_{c}, i_{d}\right]^{T}$, and $\bar{\Psi}=\bar{L} \bar{I}+\bar{\Psi}_{\mathrm{pm}}$. Also, $\bar{L}$ and $\bar{\Psi}_{\mathrm{pm}}$ can 


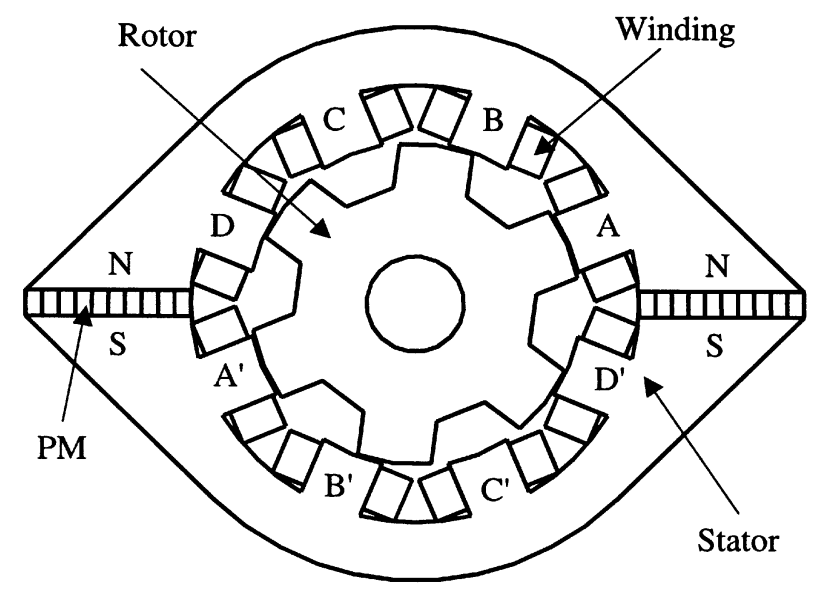

(a)
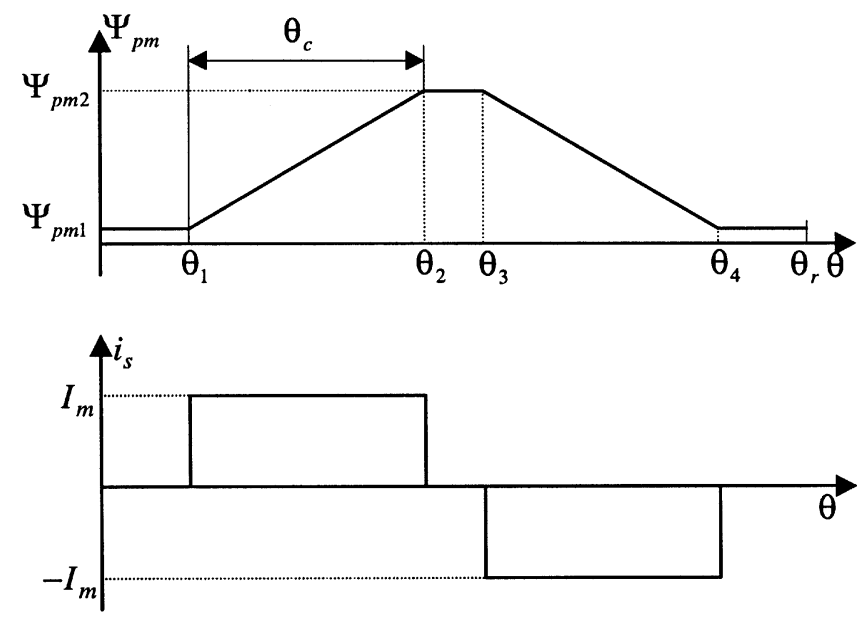

(b)

Fig. 1. DSPM motor. (a) 8/6-pole configuration. (b) Theoretical waveforms.

be written as $\bar{L}=\left[L_{x y}\right](x=a, b, c, d, y=a, b, c, d)$ and $\bar{\Psi}_{\mathrm{pm}}=\left[\Psi_{\mathrm{pma}}, \Psi_{\mathrm{pmb}}, \Psi_{\mathrm{pmc}}, \Psi_{\mathrm{pmd}}\right]^{T}$, respectively. When both of them are considered to be spatially dependent only and independent of the stator winding current, it yields

$$
\frac{d \bar{\Psi}}{d t}=\bar{L} \frac{d \bar{I}}{d t}+\frac{d \bar{L}}{d t} \bar{I}+\frac{d \bar{\Psi}_{\mathrm{pm}}}{d t}=\bar{L} \frac{d \bar{I}}{d t}+\frac{d \bar{L}}{d \theta} \bar{I} \omega_{r}+\frac{d \bar{\Psi}_{\mathrm{pm}}}{d \theta} \omega_{r} .
$$

Thus, the system equation given by (1) can be rewritten as

$$
\frac{d \bar{I}}{d t}=-\bar{L}^{-1}\left(\bar{R}+\frac{d \bar{L}}{d \theta} \omega_{r}\right) \bar{I}+\bar{L}^{-1}\left(\bar{V}-\frac{d \bar{\Psi}_{\mathrm{pm}}}{d \theta} \omega_{r}\right) .
$$

By employing the co-energy method, the expression of the total torque $T$ is obtained as

$$
\begin{aligned}
T & =\frac{\partial W^{\prime}}{\partial \theta}=\frac{\partial}{\partial \theta}\left(\frac{1}{2} \bar{I}^{T} \bar{L} \bar{I}+\bar{\Psi}_{\mathrm{pm}}^{T} \bar{I}\right) \\
& =\frac{1}{2} \bar{I}^{T}\left(\frac{\partial}{\partial \theta} \bar{L}\right) \bar{I}+\left(\frac{\partial}{\partial \theta} \bar{\Psi}_{\mathrm{pm}}\right)^{T} \bar{I}
\end{aligned}
$$

in which $T_{r}=(1 / 2) \bar{I}^{T}(\partial \bar{L} / \partial \theta) \bar{I}$ represents the reluctance torque component due to the variation of inductances, and $T_{\mathrm{pm}}=\left(\partial \bar{\Psi}_{\mathrm{pm}} / \partial \theta\right)^{T} \bar{I}$ is the PM torque component due to the interaction between the stator winding current and PM flux. By neglecting the mutual inductances $L_{x y}(x \neq y)$ of the motor, (4) can be decoupled among phases and the per-phase torque $T_{p h}$ can be expressed as

$$
T_{\mathrm{ph}}=\frac{1}{2} i^{2} \frac{d L}{d \theta}+i \frac{d \Psi_{\mathrm{pm}}}{d \theta}
$$

where $L$ is the self-inductance of each phase winding.

In order to assess the operating torque ripple, the torque ripple factor $K_{T}$ is newly defined as

$$
K_{T}=\left(\frac{T_{\max }-T_{\min }}{T_{\mathrm{av}}}\right) \times 100 \%
$$

where $T_{\max }$ is the maximum value of the total torque, $T_{\min }$ is its minimum value, and $T_{a v}$ is its average value.

Since the stator winding current is a rectangular waveform with a peak value $I_{m}$, it can be expressed as

$$
i=I_{m} \lambda
$$

where $\lambda$ is defined by

$$
\lambda=\left\{\begin{array}{cc}
+1 & \theta_{1} \leq \theta \leq \theta_{2} \\
-1 & \theta_{3} \leq \theta \leq \theta_{4} \\
0, & \text { otherwise }
\end{array}\right.
$$

Taking phase $\mathrm{A}$ as the reference, the torque production in phase $\mathrm{B}$ exhibits an angular difference of $\theta_{d}$. This $\theta_{d}$ is actually the difference between the rotor pole pitch $\theta_{r}$ and the stator pole pitch $\theta_{s}$. The torque production in subsequent phases exhibits a similar angular difference. At steady state, $T$ reaches the maximum at $\theta_{1}$, where all per-phase torques are overlapping, whereas the minimum $T$ is at $\theta_{2}$, where only two per-phase torques are overlapping. Thus, by substituting (7) and (8) into (4), the maximum total torque $T_{\max }$ and minimum total torque $T_{\min }$ can be deduced as

$$
\begin{aligned}
T_{\max }= & \left.\frac{1}{2} I_{m}^{2} \sum_{n=0}^{3} \lambda^{2}(\theta) \frac{d L(\theta)}{d \theta}\right|_{\theta=\theta_{1}+n \theta_{d}} \\
& +\left.I_{m} \sum_{n=0}^{3} \lambda(\theta) \frac{d \Psi_{\mathrm{pm}}(\theta)}{d \theta}\right|_{\theta=\theta_{1}+n \theta_{d}} \\
T_{\min }= & \left.\frac{1}{2} I_{m}^{2} \sum_{n=0}^{3} \lambda^{2}(\theta) \frac{d L(\theta)}{d \theta}\right|_{\theta=\theta_{2}+n \theta_{d}} \\
& +\left.I_{m} \sum_{n=0}^{3} \lambda(\theta) \frac{d \Psi_{\mathrm{pm}}(\theta)}{d \theta}\right|_{\theta=\theta_{2}+n \theta_{d}} .
\end{aligned}
$$

Since the operating torques in different phases are the same, the average torque of the motor can be expressed as

$$
T_{\mathrm{av}}=\frac{1}{\theta_{r}} \int_{0}^{\theta_{r}}\left(T_{a}+T_{b}+T_{c}+T_{d}\right) d \theta=\frac{4}{\theta_{r}} \int_{0}^{\theta_{r}} T_{\mathrm{ph}} d \theta
$$

where $T_{\mathrm{ph}}=T_{a}=T_{b}=T_{c}=T_{d}$. By substituting (5) into (11), this yields

$$
T_{\mathrm{av}}=\frac{4}{\theta_{r}} \int_{0}^{\theta_{r}}\left(\frac{1}{2} i^{2} \frac{d L}{d \theta}+i \frac{d \Psi_{\mathrm{pm}}}{d \theta}\right) d \theta .
$$


As shown in Fig. 1, the average value of $d L / d \theta$ over $\theta_{r}$ is zero, and the average reluctance torque component in (12) is zero. Thus, $T_{\mathrm{av}}$ becomes equal to the average PM torque component, and (12) can be rewritten as

$$
\begin{aligned}
T_{\mathrm{av}} & =\frac{4}{\theta_{r}}\left[\int_{\theta_{1}}^{\theta_{2}} I_{\mathrm{m}} \frac{d \Psi_{\mathrm{pm}}}{d \theta} d \theta+\int_{\theta_{3}}^{\theta_{4}}\left(-I_{m}\right) \frac{d \Psi_{\mathrm{pm}}}{d \theta} d \theta\right] \\
& =\frac{8}{\theta_{r}} I_{\mathrm{m}}\left(\Psi_{\mathrm{pm} 2}-\Psi_{\mathrm{pm} 1}\right) .
\end{aligned}
$$

Therefore, after substituting (9), (10), and (13) into (6), the expression of $K_{T}$ is obtained

$$
\begin{aligned}
K_{T}= & \frac{\theta_{r}}{8\left(\Psi_{\mathrm{pm} 2}-\Psi_{\mathrm{pm} 1}\right)} \\
& \times\left[\frac { 1 } { 2 } I _ { \mathrm { m } } \sum _ { n = 0 } ^ { 3 } \left(\left.\lambda^{2}(\theta) \frac{d L(\theta)}{d \theta}\right|_{\theta=\theta_{1}+n \theta_{d}}\right.\right. \\
& \left.-\left.\lambda^{2}(\theta) \frac{d L(\theta)}{d \theta}\right|_{\theta=\theta_{2}+n \theta_{d}}\right) \\
& +\sum_{n=0}^{3}\left(\left.\lambda(\theta) \frac{d \Psi_{\mathrm{pm}}(\theta)}{d \theta}\right|_{\theta=\theta_{1}+n \theta_{d}}\right) \\
& \left.\left.-\left.\lambda(\theta) \frac{d \Psi_{\mathrm{pm}}(\theta)}{d \theta}\right|_{\theta=\theta_{2}+n \theta_{d}}\right)\right] .
\end{aligned}
$$

There are some findings.

1) From (14), $K_{T}$ is related to $I_{\mathrm{m}}$. From (13), $I_{\mathrm{m}}$ is proportional to $T_{\mathrm{av}}$. Since $T_{\mathrm{av}}$ is equal to the summation of the load torque $T_{\text {load }}$ and the friction and windage torque $T_{f w}$, which is essentially constant, $K_{T}$ becomes dependent on $T_{\text {load }}$. Thus, the operating torque ripple needs to be assessed under the same load torque.

2) From (14), $K_{T}$ is proportional to $\theta_{r}$. Since $\theta_{r}=2 \pi / p_{r}$, $K_{T}$ becomes inversely proportional to $p_{r}$. Namely, the higher the number of rotor poles, the lower the torque ripple results.

3) From (14), $K_{T}$ is inversely proportional to $\Delta \Psi_{\mathrm{pm}}=$ $\left(\Psi_{\mathrm{pm} 2}-\Psi_{\mathrm{pm} 1}\right)$, which linearly relates to the conduction angle $\theta_{c}=\left(\theta_{2}-\theta_{1}\right)$. Thus, the conduction angle can be controlled in such a way to reduce or even minimize the torque ripple.

\section{B. Other Torque Ripples}

As mentioned before, there are other categories of torque ripples, namely the practical torque ripple and the manufacturing torque ripple.

First, the practical torque ripple is due to the nonideality of the motor characteristics. Fig. 2 gives a comparison between the ideal and practical PM flux waveforms of the DSPM motor. The corresponding discrepancy is mainly due to the fringing effect and the nonrectangular stator winding current. This discrepancy creates torque ripples.

Second, the manufacturing torque ripple is due to the motor imperfection during manufacturing. Fig. 3 shows a typical set of four-phase back electromotive-force (emf) waveforms of the DSPM motor. These waveforms are measured from a

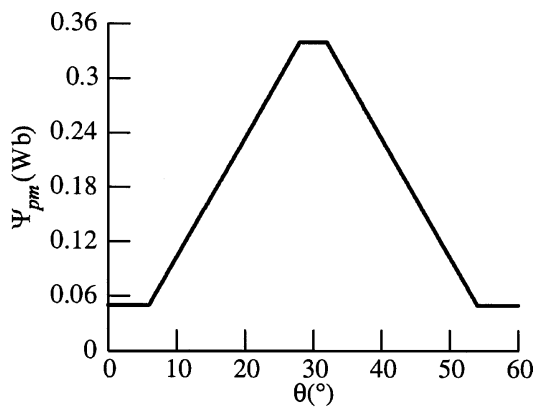

(a)

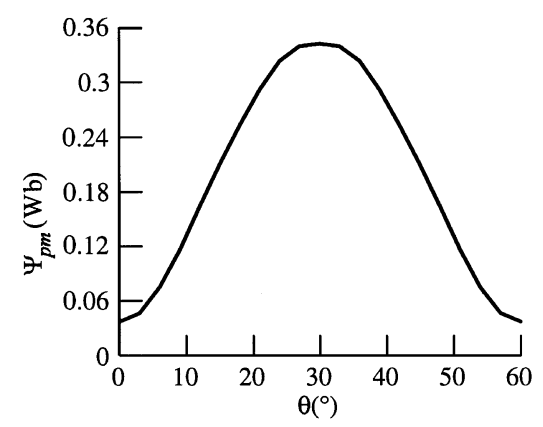

(b)

Fig. 2. PM flux waveforms. (a) Ideal. (b) Practical.

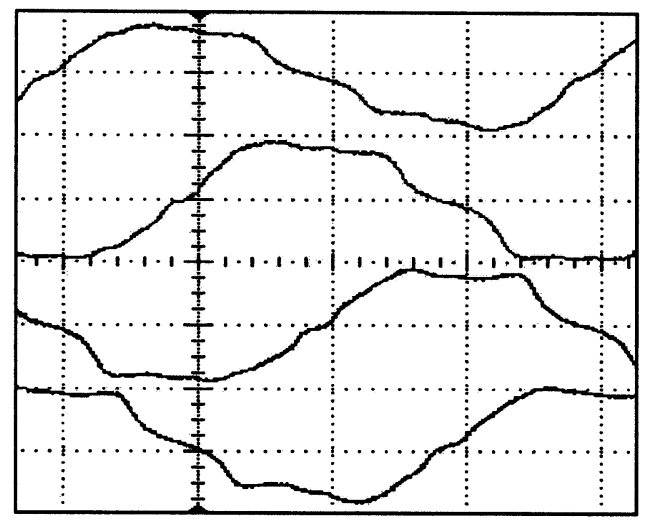

Fig. 3. Asymmetric back emf waveforms among different phases $(5 \mathrm{~ms} / \mathrm{div}$, $50 \mathrm{~V} /$ div).

realistic motor. It can be seen that there is asymmetry between the positive and negative cycles of individual phases as well as asymmetry among different phases. These asymmetries result in torque ripples.

Different from the operating torque ripple, the above two categories of torque ripples will not be analyzed or formulated in this paper. Actually, both the practical and manufacturing torque ripples are very difficult to be modeled mathematically.

\section{Conduction Angle Control}

As shown in (14), $K_{T}$ is inversely proportional to $\Delta \Psi_{\mathrm{pm}}$ which linearly relates to $\theta_{c}$. Hence, the conduction angle can be controlled in such a way to reduce or even minimize the operating torque ripple. Thus, for a given $T_{\text {load }}, K_{T}$ can be expressed as

$$
K_{T}=f\left(\theta_{1}, \theta_{2}, \theta_{3}, \theta_{4}\right)
$$




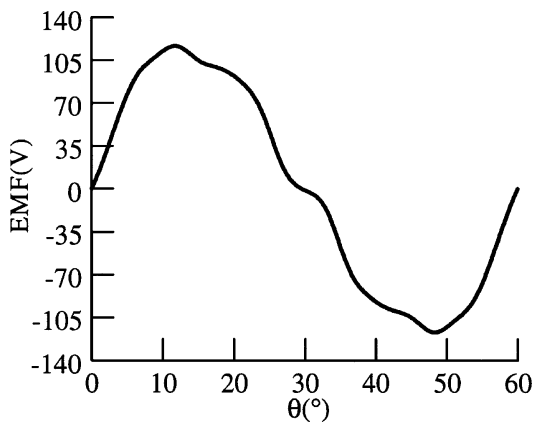

Fig. 4. Calculated back emf waveform.

TABLE I

CALCULATED INDUCTANCES

\begin{tabular}{cccc}
\hline$\theta\left({ }^{\circ}\right)$ & 0 & 15 & 45 \\
$L^{+}(\mathrm{mH})$ & 8.63 & 24.03 & 28.15 \\
$L^{-}(\mathrm{mH})$ & 8.62 & 26.93 & 36.67 \\
$L(\mathrm{mH})$ & 8.625 & 25.48 & 32.41 \\
\hline
\end{tabular}

\section{A. Simulation Results}

Before simulating the torque ripple waveforms, both $\Psi_{\mathrm{pm}}$ and $L$ need to be determined. In order to obtain their variations with respect to $\theta$, finite-element analysis of the aforementioned DSPM motor is conducted. Hence, the calculated back emf waveform at the rated speed of $1500 \mathrm{r} / \mathrm{min}$ is shown in Fig. 4. The calculated values of $L$ at three typical angular positions are listed in Table I, where $L^{+}$and $L^{-}$denote the values corresponding to the strengthening and weakening actions of the stator winding current of $1 \mathrm{~A}$ to the PM flux, respectively, and $L$ is the average value of $L^{+}$and $L^{-}$. By using (4), the calculated torque waveforms, including $T_{\mathrm{pm}}, T_{r}$ and their resultant $T$, under the rated $T_{\text {load }}$ of $4.78 \mathrm{Nm}$ are shown in Fig. 5. It can be found that $T_{\mathrm{pm}}$ is significantly dominant over $T_{r}$.

In order to illustrate the effect of control angles on the operating torque ripple, computer simulations are carried out based on two sets of control angles:

- Case A: $\theta_{1}=5^{\circ}, \theta_{2}=25^{\circ}, \theta_{3}=35^{\circ}, \theta_{4}=55^{\circ}$, $T_{\text {load }}=4.78 \mathrm{Nm}$;

- Case B: $\theta_{1}=2^{\circ}, \theta_{2}=28^{\circ}, \theta_{3}=32^{\circ}, \theta_{4}=58^{\circ}$, $T_{\text {load }}=4.78 \mathrm{Nm}$.

When operating at Case A, the calculated waveform of $T$ is shown in Fig. 6(a). The corresponding $K_{T}$ is $81 \%$. On the other hand, when operating at Case B, the calculated waveform of $T$ is shown in Fig. 6(b). The corresponding $K_{T}$ is $68 \%$. Hence, the reduction of operating torque ripple is $13 \%$. It indicates that at a given $T_{\text {load }}$, the selection of proper control angles can alter the operating torque ripple. Nevertheless, the selection of control angles is limited by the commutation angle for current commutation. Thus, the controllable ranges of $\theta_{1}, \theta_{2}, \theta_{3}$, and $\theta_{4}$ are [ $2^{\circ}$, $\left.10^{\circ}\right],\left[20^{\circ}, 28^{\circ}\right],\left[32^{\circ}, 40^{\circ}\right]$, and $\left[50^{\circ}, 58^{\circ}\right]$, respectively.

\section{B. Experimental Results}

After prototyping the aforementioned DSPM motor, a series of experimentation is conducted. First, the motor is coupled to a dc motor, and operates as a generator. Hence, its open-circuited

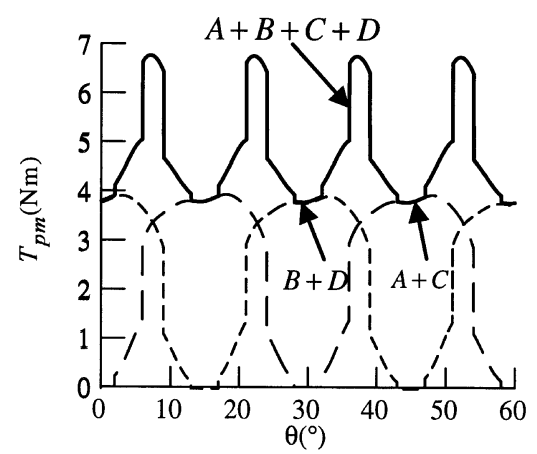

(a)

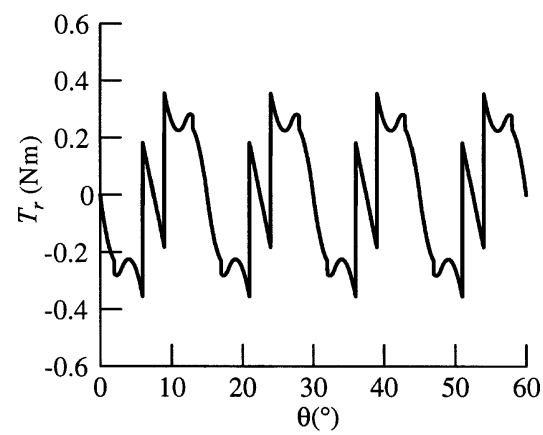

(b)

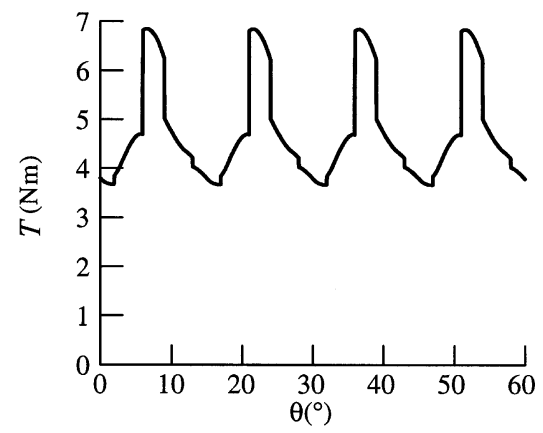

(c)

Fig. 5. Torque waveforms. (a) PM. (b) Reluctance. (c) Resultant.

back emf at the rated speed is measured as shown in Fig. 7. It can be seen that it closely agrees with the calculated waveform shown in Fig. 4. Second, the inductance values at three typical angular positions are measured by using the peak value method [10] which takes into account the influence of the stator winding current on the PM flux. As shown in Table II, $L^{+}$and $L^{-}$are the measured inductance values corresponding to the strengthening and weakening actions of the stator winding current of $1 \mathrm{~A}$ to the PM flux, respectively, and $L$ is the average value of $L^{+}$and $L^{-}$. Compared with those calculated values listed in Table I, the measured values closely agree with the calculated ones. Therefore, the calculated $\Psi_{\mathrm{pm}}$ and $L$ with respect to $\theta$ are verified.

In order to directly measure the torque ripple of the DSPM motor, a transient torque transducer is mounted between the motor and the dynamometer. For the sake of illustration, the stator winding current is also measured by a current transducer. The measured torque and current waveforms of the motor operating at Cases A and B are shown in Fig. 8(a) and (b), respectively. As expected, the measured torque waveforms have a significant discrepancy with those calculated waveforms shown 


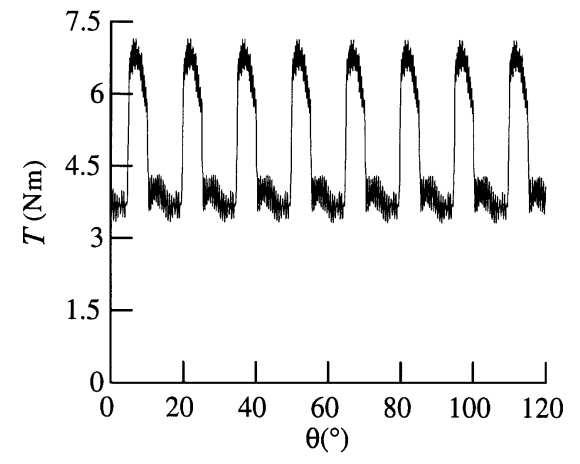

(a)

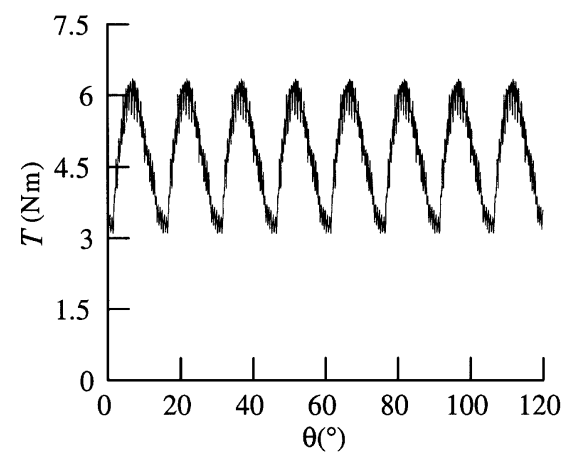

(b)

Fig. 6. Calculated operating torque ripples. (a) Case A. (b) Case B.

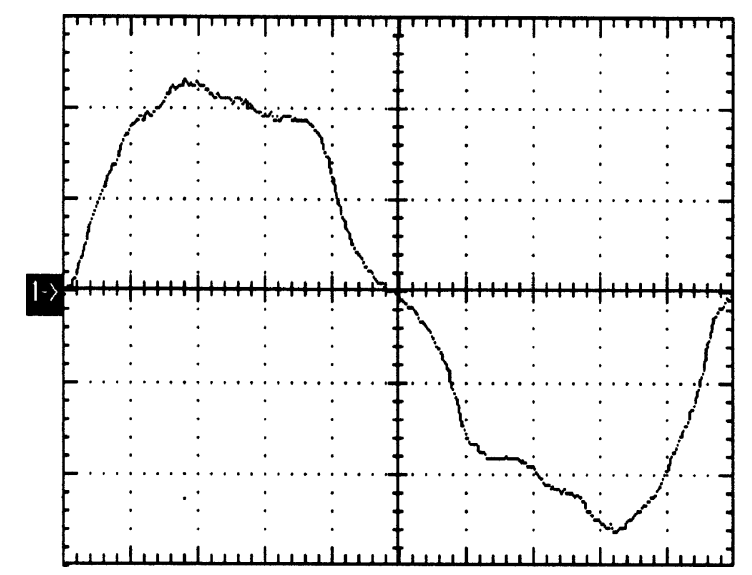

Fig. 7. Measured back emf waveform ( $50 \mathrm{~V} / \mathrm{div}, 0.7 \mathrm{~ms} / \mathrm{div})$.

in Fig. 6. This discrepancy is due to the fact that the calculated torque waveforms in Fig. 6 take into account the operating torque ripple only, whereas the measured torque waveforms consist of all torque ripples, namely the operating, practical, and manufacturing torque ripples. Notice that both the practical and manufacturing torque ripples are very difficult to be modeled mathematically. Nevertheless, these torque ripples can be roughly considered as a constant value at a given $T_{\text {load }}$.

From Fig. 8(a), it can be found that the measured $K_{T}$ is $122 \%$ when the motor is operating at Case A. Compared with the calculated $K_{T}$ of $81 \%$, there is a difference of $41 \%$ which can be considered as the contributions from both the practical and manufacturing torque ripples. On the other hand, Fig. 8(b) shows that the measured $K_{T}$ is $108 \%$ when the motor is operating at
TABLE II

MEASURED INDUCTANCES

\begin{tabular}{cccc}
\hline$\theta\left({ }^{\circ}\right)$ & 0 & 15 & 45 \\
$L^{+}(\mathrm{mH})$ & 8.77 & 21.7 & 29.05 \\
$L^{-}(\mathrm{mH})$ & 9.08 & 26.81 & 36.88 \\
$L(\mathrm{mH})$ & 8.93 & 24.26 & 32.97 \\
\hline
\end{tabular}

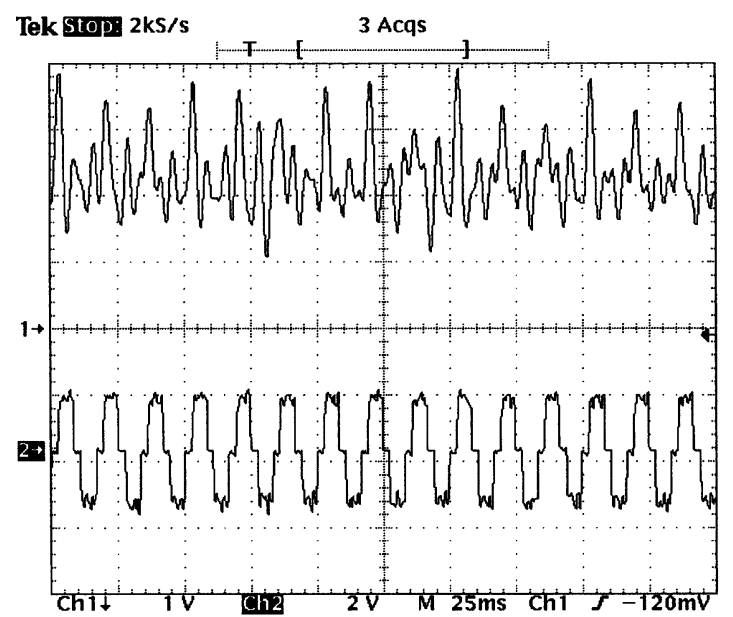

(a)

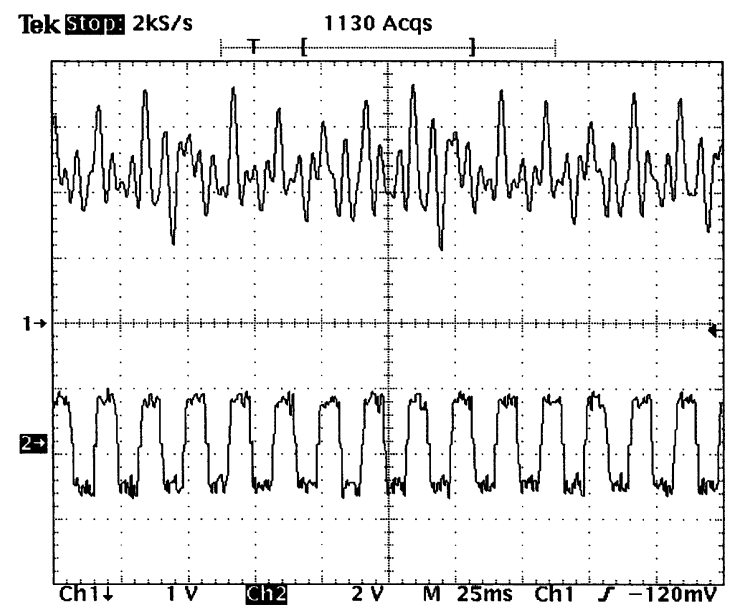

(b)

Fig. 8. Measured torque and current waveforms. (a) Case A ( $25 \mathrm{~ms} / \mathrm{div}, 2.2$ Nm/div, 3.33 A/div). (b) Case B (25 ms/div, 2.2 Nm/div, 3.33 A/div).

Case B. After subtracting the $41 \%$ contributed from the practical and manufacturing torque ripples, the resulting $K_{T}$ of $67 \%$ (contributed from the operating torque ripple) closely agrees with the calculated $K_{T}$ of $68 \%$.

It should be noted that the above assumption on using a constant value to account for practical and manufacturing torque ripples is valid only for a particular load or set of control angles. At different loads or control angles, the value of practical and manufacturing torque ripples will be different. Thus, the proposed conduction angle control is to reduce or minimize the operating torque ripple only. The corresponding control angles may have a slight discrepancy with the actual optimal control angles for minimization of all categories of torque ripples. 


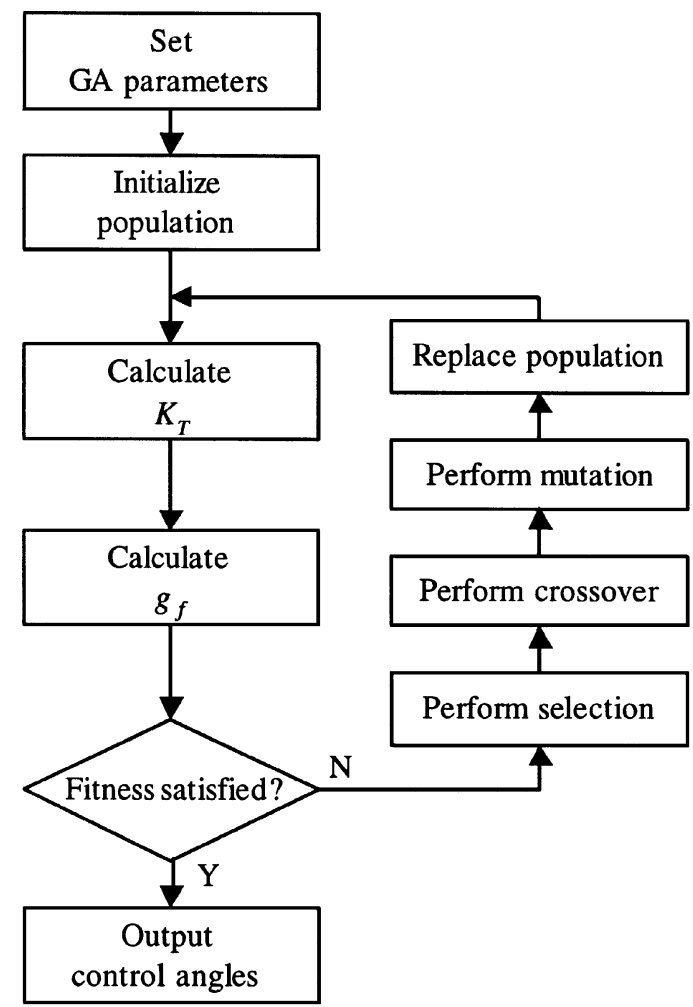

Fig. 9. GA optimization of control angles.

\section{TORQUe RIPPLE MiNIMIZATION}

Although the aforementioned conduction angle control can reduce the operating torque ripple, the selection of proper control angles is $a d h o c$. It is desirable to optimize those conduction angles in such a way that the torque ripple can be minimized. Since (15) is not a simple function, it is hardly possible to carry out the optimization by using analytical methods. Thus, the GA is newly adopted for such optimization.

The basic principle of GA is to emulate natural evolution, namely the survival-of-the-fittest mechanism in nature [7]. A possible solution of a problem is an individual which can be represented by a set of parameters. These parameters are regarded as the genes of a chromosome, and can be represented by a string of binary values. A positive value, generally termed as the fitness, is used to reflect the degree of goodness of the chromosome for the problem. In each cycle of genetic operation, termed as the evolving process, a subsequent generation is created from the chromosomes in the current population. The cycle of evolution is repeated until a termination criterion is reached. This criterion can be set by the amount of variations between successive generations, the predefined fitness, or the number of evolution cycles.

The GA optimization is effective at solving complex, combinatorial, and related problems [8], [9]. It is a global optimizer while other common techniques such as the conjugate gradient and quasi-Newton methods are termed as local optimizers. The key difference between the GA and other local optimizers is that the GA one is essentially independent of the initial conditions while the local one is highly dependent on the initial guess. Moreover, the GA optimizer can readily handle discontinuous and nondifferentiable functions.

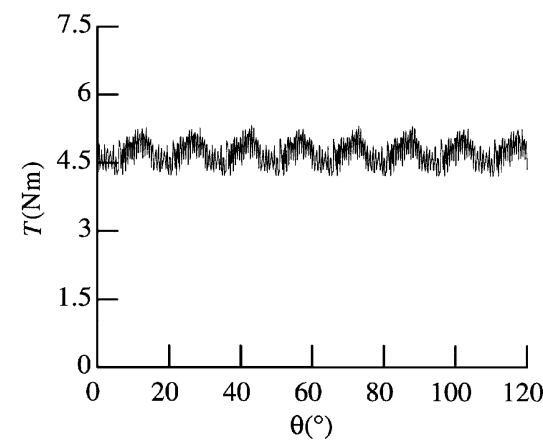

Fig. 10. Calculated operating torque ripples using GA optimization.

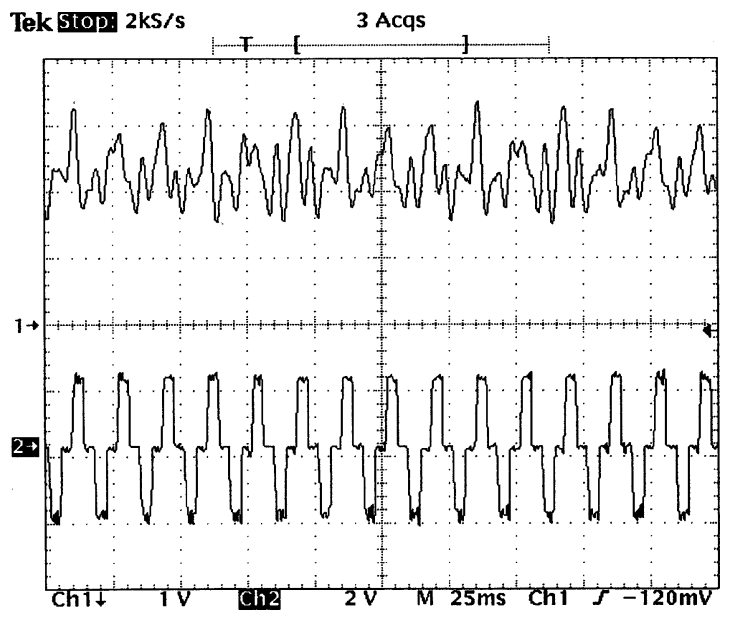

Fig. 11. Measured torque and current waveforms using GA optimization (25 $\mathrm{ms} / \mathrm{div}, 2.2 \mathrm{Nm} / \mathrm{div}, 3.33 \mathrm{~A} / \mathrm{div})$.

By nature, the GA optimizer is inherently a maximizer. In order to search a minimum of the torque ripple, the fitness function for minimizing $K_{T}$ is defined as

$$
g_{f}=K_{\max }-K_{T}
$$

where $K_{\max }$ is a positive number larger than the largest expected value of $K_{T}$.

Based on computer simulation of the GA optimization shown in Fig. 9, the optimal control angles under the rated $T_{\text {load }}$ are obtained, namely $\theta_{1}=6.4^{\circ}, \theta_{2}=21^{\circ}, \theta_{3}=36.4^{\circ}, \theta_{4}=51^{\circ}$. Hence, the calculated waveform of $T$ is shown in Fig. 10. The corresponding $K_{T}$ is $27.4 \%$. Compared with $K_{T}=81 \%$ at Case $\mathrm{A}$, the operating torque ripple using the GA is significantly reduced by $53.6 \%$.

In order to realistically assess the GA optimizer, it is implemented by digital hardware. Under the rated $T_{\text {load }}$, the optimal control angles are online deduced as $\theta_{1}=7.2^{\circ}, \theta_{2}=22.8^{\circ}$, $\theta_{3}=37.2^{\circ}, \theta_{4}=52.81^{\circ}$. The corresponding torque and current waveforms are measured as shown in Fig. 11. It can be found that $K_{T}$ is $62 \%$, which includes the practical and manufacturing torque ripples. After subtracting the $41 \%$ contributed from the practical and manufacturing torque ripples, the resulting $K_{T}$ becomes $21 \%$ (contributed from the operating torque ripple) which is lower than the calculated $K_{T}$ of $27.4 \%$. This further improvement is due to the fact that the online GA optimizer can also reduce the practical and manufacturing torque ripples in a trial-and-error way. 


\section{CONCLUSION}

In this paper, the torque ripple of DSPM motors has been analyzed, and the torque ripple factor has been newly derived to assess the operating torque ripple. To reduce the operating torque ripple, a new conduction angle control approach has been proposed and verified. The GA optimization has also been adopted to optimize the control angles, hence, minimizing the torque ripple. Both computer simulation and experimental results have confirmed the effectiveness of the proposed approach. This approach is so general that it can readily be extended to other salient-pole motors.

\section{REFERENCES}

[1] Y. Liao, F. Liang, and T. A. Lipo, "A novel permanent magnet motor with doubly salient structure," IEEE Trans. Ind. Appl., vol. 31, no. 5, pp. 1069-1078, Sep./Oct. 1995.

[2] R. Deodhar, S. Anderson, I. Boldea, and T. J. E. Miller, "The flux-reversal machine: a new brushless doubly-salient permanent magnet machine," IEEE Trans. Ind. Appl., vol. 33, no. 4, pp. 925-934, Jul./Aug. 1997.

[3] M. Cheng, K. T. Chau, C. C. Chan, E. Zhou, and X. Huang, "Nonlinear varying-network magnetic circuit analysis for doubly salient permanent magnet motors," IEEE Trans. Magn., vol. 36, no. 1, pp. 339-348, Jan. 2000.

[4] M. Cheng, K. T. Chau, and C. C. Chan, "Static characteristics of a new doubly salient permanent magnet motor," IEEE Trans. Energy Convers., vol. 16, no. 1, pp. 20-25, Mar. 2001.

[5] C. X. Wang, I. Boldea, and S. A. Nasar, "Characterization of three phase flux reversal machine as an automotive generator," IEEE Trans. Energy Convers., vol. 16, no. 1, pp. 74-80, Mar. 2001.

[6] M. Cheng, K. T. Chau, and C. C. Chan, "New split-winding doubly salient permanent magnet motor drive," IEEE Trans. Aerosp. Electron. Syst., vol. 39, no. 1, pp. 202-210, Jan. 2003.

[7] K. F. Man and K. S. Tang, "Genetic algorithms for control and signal processing," in Proc. IEEE Int. Conf. Industrial Electronics, Control Instrumentation, 1997, pp. 1541-1555.

[8] J. M. Johnson and Y. Rahmat-Samii, "Genetic algorithm optimization for aerospace electromagnetic design and analysis," in Proc. IEEE Aerospace Applications Conf., 1996, pp. 87-102.

[9] W. A. Chang and R. S. Ramakrishna, "A genetic algorithm for shortest path routing problem and the sizing of populations," IEEE Trans. Evol. Comput., vol. 6, no. 6, pp. 566-579, Dec. 2002.

[10] M. Cheng, Q. Sun, E. Zhou, and K. T. Chau, "New methods of measuring inductance of doubly salient permanent magnet motors," Elect. Power Compon. Syst., vol. 30, no. 11, pp. 1127-1135, 2002.

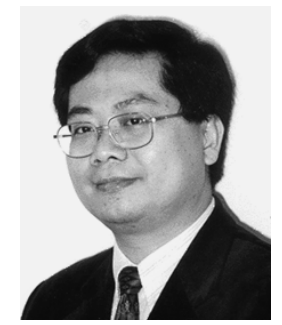

K. T. Chau (M'89-SM'04) received the first-class honors B.Sc. (Eng.), M.Phil., and Ph.D. degrees in electrical and electronic engineering from The University of Hong Kong, Hong Kong, in 1988, 1991, and 1993, respectively.

He is currently an Associate Professor at The University of Hong Kong. His teaching and research interests focus on three main areas: power converters, machines and drives, and electric vehicles. In these areas, he has authored more than 100 published refereed technical papers and several industrial reports. He has also served as chair and organizing committee member for many international conferences. He is the coauthor of a monograph, Modern Electric Vehicle Technology (London, U.K.: Oxford Univ. Press, 2001).

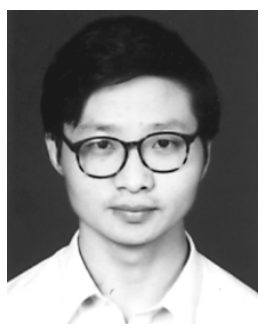

Qiang Sun was born in Anhui Province, China. He received the B.Sc. degree in electrical engineering from Hefei University of Technology, Hefei, China, in 1991, and the M.Sc. Eng. degree in electrical engineering in 1999 from Southeast University, Nanjing, China, where he is currently pursuing the Ph.D. degree.

His interests include electrical machines and drives, intelligent control, and power electronics. $\mathrm{He}$ has authored five papers on these topics.

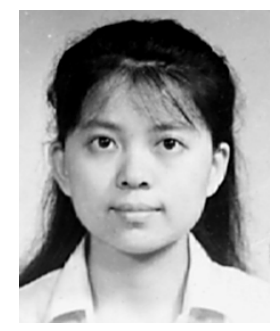

Ying Fan (S'04) received the B.Sc. Eng. and M.Sc. Eng. degrees from the Department of Electrical Engineering, Nanjing University of Astronautics and Aeronautics, Nanjing, China, in 1991 and 1996, respectively. She is currently pursuing the Ph.D. degree in electrical and electronic engineering at The University of Hong Kong, Hong Kong.

Her research interests focus on electric machine design, motor drive control, power electronics, modeling, and simulation.

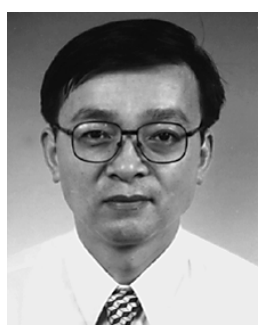

Ming Cheng (M'01-SM'02) received the B.Sc. Eng. and M.Sc. Eng. degrees from the Department of Electrical Engineering, Southeast University, Nanjing, China, in 1982 and 1987, respectively, and the Ph.D. degree from the Department of Electrical and Electronic Engineering, The University of Hong Kong, Hong Kong, in 2001.

Currently, he is the Head and a Professor of the Department of Electrical Engineering, Southeast University, where he has been since 1987. His teaching and research interests include electrical machines, motor drives, and power electronics. He has published many technical papers and holds five patents in these areas. 